\section{Research}

Earlier research in psychiatry, for example by the pioneering psychiatrist Burton-Bradley (1973), identified common forms of mental illness in the country and elicited the public's views about the aetiology of mental illness (often attributed to sorcery). Later research confirmed the occurrence of substance misuse (Johnson, 1991), post-traumatic stress disorder (Johnson, 1989) and so on. However, despite the requirement for all MMed students to carry out research as part of their training, most make no attempt to get their work published after qualifying. As a result, there is still a dearth of research in psychiatry in Papua New Guinea.

\section{Professional groups}

The Papua New Guinea Psychiatric Association comprises all psychiatrists and psychiatric registrars in the

\section{Non-governmental organisations}

to be smuggled into Australia in exchange for guns, which are then used in tribal fights. country - a total of II members.

of in-patient facilities at the provincial level and an increase in substance misuse, especially cannabis. Cannabis grows readily in the highlands of Papua New Guinea and the number of patients with cannabisrelated psychosis has risen greatly over the past 15 years as the cultivation of the plant has increased, both for local consumption and as a cash crop to be smuggled into Australia in exchange for guns, which are then used in tribal fights.

Traditional beliefs about mental illness (e.g. sorcery) also hinder some patients from accessing services or adhering to the treatment prescribed.

An inadequate road network means that patients who need referral to the only psychiatric hospital but who are too disturbed to fly are frequently held not in general hospitals but in local police cells as the only available secure place. They are held until they are stable enough to be transferred by commercial aircraft without posing a risk to others on board.

\section{References}

Burton-Bradley, B. ( 1 973) Longlong: Transcultural Psychiatry in Papua New Guinea. Port Moresby: Public Health Department.

Johnson, F. ( 1 989) Post-traumatic stress disorder. Papua New Guinea Medical Journal, 32, 87-88.

Johnson, F. ( $99 \mid$ ) A comparative study of alcohol-related problems among a group of university students and a group of clerks in the National Capital District, Papua New Guinea. Medicine and Law, I0, 457-467.

Ministry of Health (2000) Papua New Guinea. National Health Plan 2001-2010: Health Vision 2010. Vol. I: Policy Directions. Vol. II: Program Policies and Strategies. Port Moresby: Ministry of Health.

National Statistics Office (2003) National Census 2000. Port Moresby: National Statistics Office. Available at http://www.nso. gov.pg/. Last accessed 20 April 2006

UNICEF (2006) The State of the World's Children 2006: Excluded and Invisible. New York: UNICEF. Available at http://www.unicef. org/sowc06/statistics/database.php. Last accessed 20 April 2006.

\section{Challenges}

The challenges include a shortage of trained staff, frequent shortages of basic psychiatric drugs, the absence
World Health Organization (2005) Mental Health Atlas. Geneva: WHO. Available at http://www.who.int/mental health/evidence/ atlas. Last accessed 20 April 2006.

\title{
Psychiatry in Bangladesh
}

\section{Rezaul Karim, FCPS, ${ }^{1}$ Fakhruzzaman Shaheed, MD, ${ }^{2}$ and Siddhartha Paul ${ }^{3}$}

${ }^{1}$ Professor of Psychiatry and Principal, Sylhet MAG Osmani Medical College, Sylhet, Bangladesh email psyrkarim@yahoo.com

${ }^{2}$ Assistant Registrar, Psychiatry, Sylhet MAG Osmani Medical College and Hospital ${ }^{3}$ MPhil (Psychiatry) Student, Sylhet MAG Osmani Medical College

\footnotetext{
The People's Republic of Bangladesh is located in South Asia. The total land area of Bangladesh is $147570 \mathrm{~km}^{2}$. Its total population in $200 \mathrm{I}$ was about 123 million. The population growth rate is I.47\%; of the total population, $75 \%$ live in rural areas and $25 \%$ in urban areas (Bangladesh Bureau of Statistics, 2000).
}

\section{Health indicators}

Life expectancy at birth in 1998 was estimated to be 61 years for both sexes. The infant mortality rate was 57 per 1000 live births in 1998. The number of hospital beds is 43 | 43 and the number of registered physicians is 30869 (Bangladesh Bureau of Statistics, 2000). 


\section{History of psychiatric services in Bangladesh}

In what is now Bangladesh, there were no mental health facilities until 1947, when India was divided. (Psychiatric patients had to go to the Central European Asylum in Ranchi, which was too far away for many people.) In that situation the government (of what was then East Pakistan) decided to establish a mental hospital, and in 1957 one was opened in Pabna, a district town $175 \mathrm{~km}$ from the capital, Dhaka. Initially it was a 50-bed hospital, but it grew to become today a 500-bed hospital. In 1974 Dhaka Medical College introduced a mental health service. This service was then extended to the Institute of Postgraduate Medicine and Research (now Bangabhandu Sheikh Mujib Medical University, BSMMU) and other medical colleges, as well as to the Institute of Mental Health and Research. This service included both outpatient and in-patient departments. At present, all 13 government medical colleges and hospitals and some of the non-government medical college hospitals provide psychiatric services, both out-patient and inpatient.

\section{Prevalence of psychiatric disorder}

Psychiatric disorder is common in Bangladesh, as in any other country, but the psychiatric service at present is confined to Pabna Mental Hospital, the Institute of Mental Health, the BSMMU and the medical college hospitals (Islam et al, 1993). Although the results of a recent national survey of psychiatric morbidity are yet to published, the evidence from smaller surveys suggests that psychiatric disorder is prevalent in both the urban and rural communities. In a survey of the rural population of Dasherkandi (a village near Dhaka) it was found that 29 per 1000 people suffered from psychiatric disorder, and an additional 36 per 1000 had both a psychiatric and a physical disorder (Chowdhury et al, 1981).

In another study it was found that $29 \%$ of patients seen in a medical general practice during the course of I year were suffering from a purely psychological or emotional disorder (Alam, 1978).

At the medical out-patient department of the Institute of Postgraduate Medical Research, it was found that $31 \%$ of patients had a purely psychological condition and an additional I 5\% had a condition with both organic and psychogenic features (Chowdhury et al, 1975).

In a study of 600 patients attending a psychiatric clinic in Chittagong city, schizophrenia and affective disorder were found in $30 \%$ and $25 \%$ of patients, respectively. Neurosis and personality disorder in combination were found in 30\%. Organic disorder and learning disabilities were found in $7 \%$ and $3 \%$ respectively (Ahmed, 1978).

\section{Medical education}

\section{Undergraduate education}

Psychiatry is included in the undergraduate curriculum. The course comprises 15 lectures (I hour each) and 15 days of clinical clerkship in the fourth-year MBBS class, which is mandatory for all students. In the MBBS, $12.5 \%$ of marks are allotted to mental health in the written final examination.

\section{Postgraduate education}

Postgraduate courses in Bangladesh include fellowship and membership of the Bangladesh College of Physicians and Surgeons (FCPS and MCPS), master of philosophy (MPhil) and doctor of medicine (MD). The FCPS course is run by an autonomous body following the curriculum of the MRCPsych. It has part I and part II examinations and also requires 2 years of full-time clinical experience. There have been 34 fellows to date. The MD course is run by the BSMMU. It has had one successful student complete the course and another II are currently taking it. The MD is a 5-year course, which includes 3 years of training. The MPhil course is run by both the BSMMU and Sylhet MAG Osmani Medical College. It is a 3-year course, including I year of residential training. So far 25 students have gained the MPhil and 18 students are presently on the course. At the end of both the MD and the MPhil courses, students have to submit a thesis, and FCPS students have to submit a dissertation.

\section{Training}

The BSMMU, the Institute of Mental Health and Research and the 13 government-run medical colleges provide postgraduate training in psychiatry. Doctors interested in psychiatry work as 'indoor' medical officers, assistant registrars or honorary medical officers. The institutes do not pay the nongovernment doctors, who work as honorary medical officers. The training is full time and residential.

\section{Child psychiatry}

Child psychiatry has not been developed in Bangladesh, although there is a child psychiatry wing at the BSMMU and another child psychiatry department at the Institute of Mental Health and Research. The country has only three psychiatrists trained (abroad) in child psychiatry.

\section{Psychotherapy}

Psychotherapy (which is still in a rudimentary state) is mostly done by psychiatrists. In the University of Dhaka there is a clinical psychology department. Students are trained in psychotherapy at the psychiatry department of the BSMMU.
Doctors interested in psychiatry work as 'indoor' medical officers, assistant registrars

or honorary medical officers.

The institutes

do not pay the non-government doctors, who work as honorary medical officers.

The training is

full time and residential. 


\section{Research}

Research is mainly epidemiological, although some research into different disorders and on drug misuse, suicide and child psychiatry is ongoing. The Bangladesh Association of Psychiatrists publishes journals.

\section{Mental health professionals}

There are 73 psychiatrists nationally. The Institute of Mental Health and Research is training medical graduates and primary health workers throughout the country. In total, 2048 doctors and some 4000 health workers have been trained in psychiatry.

\section{There are} approximately 800 beds sanctioned for psychiatric patients in government hospitals. In non-government sectors, there are about 1000 psychiatric beds, most of which are occupied by drug misusers, whereas in the government sector people with a psychosis occupy almost all the beds.

\section{Mental health services in Bangladesh}

As the number of psychiatrists is low relative to the size of the population, psychiatric patients are taken care of by psychiatrists, doctors trained in psychiatry, doctors practising relevant specialties and general practitioners. There is no formal referral system, although patients are referred by other health professionals to psychiatrists for proper management.

Many patients attend psychiatrists after 'referral' from people in their local community. Some patients are now referred to psychiatrists by traditional healers, faith healers and unqualified medical practitioners (socalled 'village doctors'). There are approximately 800 beds sanctioned for psychiatric patients in government hospitals. In non-government sectors, there are about 1000 psychiatric beds, most of which are occupied by drug misusers, whereas in the government sector people with a psychosis occupy almost all the beds. There is one government drug addiction treatment centre, with 75 beds, situated in Dhaka.

Doctors who have been trained in psychiatry work mostly in primary care centres. They are supposed to take care of the psychiatric patients in their areas, but there are no statistics regarding the patient care undertaken by these doctors. Also, there are no refresher courses for these trained doctors, so they are not in touch with recent advances in psychiatry.

\section{Mental health legislation and policy}

Still there is no mental health act in Bangladesh. The Indian Lunacy Act 1912 (modified in 1957 and 1973) is generally followed. A draft mental health policy has been formulated by the Ministry of Health in collaboration with the World Health Organization and the Bangladesh Association of Psychiatrists; this policy is presently at the Law Ministry for finalisation.

\section{Human rights}

As mentioned above, a large number of psychiatric patients receive treatment from traditional and faith healers, local religious leaders and practitioners of indigenous medicine. They believe that illness is related to supernatural influences, and so many patients are reluctant to consult practitioners of modern allopathic medicine. The non-medical healers are less concerned about the human rights of patients and people generally are not conscious of the proper rights of those with a mental disorder. In some special circumstances, for example when these patients are the focus of stories in the news media, then human rights activists often come forward to help them. Practising psychiatrists and the Association of Psychiatrists have very little influence in maintaining the human rights of psychiatric patients in the community, but in hospital settings psychiatric patients are treated as general patients.

\section{Associations}

There are two psychiatric associations: the Bangladesh Association of Psychiatrists (BAP), of which all psychiatrists practising in Bangladesh are members; and the Forum of Psychiatry, which has emerged only recently.

\section{Overview}

Education and services in psychiatry are gradually increasing, but still psychiatrists and psychiatric services tend to be available only in big cities. Most of the psychotropic medications are available in Bangladesh. On the other hand, psychotherapy is not widely available. Bangladesh lacks a mental health act. The BAP has been struggling to have an act passed and to expand psychiatric services in remote areas.

\section{References}

Ahmed, S. U. (1978) Analysis of the epidemiological data of 600 psychiatric patients. Bangladeshi Medical Research Council Bulletin, 4, 43-48.

Alam, M. N. (1978) Psychiatric morbidity in general practice. Bangladeshi Medical Research Council Bulletin, 4, 38-42.

Bangladesh Bureau of Statistics (2000) Statistical Yearbook of Bangladesh 2000, pp. 5-10. Dhaka: Bangladesh Bureau of Statistics.

Chowdhury, A. K. M. N., Selim, M. \& Sakeb, N. (1975) Some aspects of psychiatric morbidity in the out-patient population of a general hospital. Bangladeshi Medical Research Council Bulletin, I, 5I-59.

Chowdhury, A. K. M. N., Alam, M. N. \& Keramat, S. M. (198I) Dashkerkandi project studies: demography morbidity and mortality in rural community of Bangladesh. Bangladeshi Medical Research Council Bulletin, 7, 22-39.

Islam, H., Mullick, M. S. I. \& Khanam, M. (1993) Sociodemographic characteristics and psychiatric morbidity of out-patients in the Institute of Mental Health and Research. Journal of the Institute of Postgraduate Medicine and Research, 8, 69-78. 